find that proper accommodation and suitable supervision are manifestly wanting.

Dr. Williams's suggestions for the visitation of such patients by paid officials, and for the weekly allowance of money to these poor people, are open to two objections. One is, that in the present state of the law they are not practicable; or next, if practicable, they would insure "that infliction of further pecuniary burdens on the already over-taxed ratepayers" which Dr. Williams deprecates.

I am, Sir, your obedient servant,

P. Northall Lawrie,

Dec. 18th, 1871.

Chairman of the Hanwell Asylum Committee.

\section{THE THEORY AND TREATMENT OF CHOLERA.} To the Editor of The LANCET.

Sin,-It is perhaps unnecessary at the present season to occupy the attention of your readers with any further remarks on the true theory and treatment of cholera. But before the discussion is closed, it may be useful to direct notice to the following important admissions, which, so far as can be gathered from his remarks on the subject, are expressed or implied in Dr. Johnson's communication to The LANCET of Dec. 9th, in reply to my late paper "On some Physiological Errors connected with Cholera."

1. That temporary albuminuria is not conclusive evidence of blood-poisoning.

2. That cyanosis is not a diagnostic sign of cholera.

3. That the secretion of urine by the fotus is not "even more scanty than that of a patient in cholera collapse."

When Dr. Johnson pleads that my so-called "merciless criticism" of his statements respecting a certain "interesting physiological correlation," to which he has referred at some length, is unjust, because a lately published paper on the subject (Aug. 1870) has been selected instead of one of a much earlier date (Feb. 1866), he simply succeeds in illustrating the truth of my remark, that the unsoundness of his theory "becomes more apparent after every fresh effort on the part of the author to retrieve his position."

"Our failures may be as instructive as our successes" was the sad but hopeful comment of Dr. Johnson himself on the treatment of cholera at King's College Hospital in 1866, for no temporary success of a theory can justify any continued failure in treatment; and it is reassuring to find that the lesson learnt on that occasion has not been forgotten. For although the opinions of the distinguished Professor of Medicine at King's College respecting the nature of the disease are still apparently unchanged, yet his opinions respecting its treatment have since undergone a marked and progressive change for the better, in consequence of which he no longer advocates " the necessity of a cathartic method of treatment in the widest sense of that term "; and his theory is now very far from being in strict accordance with his practice. "The good effects of heat" were, we have been assured by Dr. Johnson in his Notes on Cholera in 1866, "unquestionable" ; whilst cold water was decidedly injurious, in consequence of its "diminishing the vascularity of the mucous membrane, and thus interfering with the excretion of the morbid poison." It would be, of course, impossible for me to fix the exact date at which the decisive change in Dr. Johnson's opinions on the treatment of cholera occurred. It is sufficient to know that a very great and a very praiseworthy change of opinion has lately happened, and that he has at last kindly consented to be guided by the experience of others in the revision of his plans for the future treatment of the disease. With reference to this subject, it is interesting to note that in place of hot liquids to drink, and of hot injections into the rectum, he is, for the present, inclined to give an abundant supply of cold water; and we have been quietly led to infer that castor oil may, in most curable cases, be safely omitted.

We are quite content to rest and be thankful, since so much has been gained in the warfare against a fatal error. "The copious imbibition of pure cold water," with perhaps the addition, which has been lately recommended, of a little phosphoric acid, "will suffice for the cure of most curable cases" ; and when the pathology of the disease is better understood, it may probably be admitted that the applica- tion of castor oil and hot liquids to the alimentary mucous membrane during choleraic collapse is painfully suggestive of the application of petroleum to a house on fire.

I am, Sir, your humble servant,

Park-place, Upper Baker-street, Wruliam Sedgwick. December 11th, 1871 .

** This controversy must really end now.

\section{THE SANITARY STATE OF WEST NEWTON.}

To the Editor of THE LANCET.

Sir,-In your report on West Newton one or two inaccuracies occur, which I trust you will allow me to correct. I should not presume to do so, but that my local knowledge extends over eleven years, during which time $I$ have attended the majority of the sick in the village.

The wells are not all shallow, but there seem to be two water-bearing strata at least, besides that supplying the surface water, and in two epidemics of typhoid four distinct water-supplies have been used by different batches of patients.

In 1860 , after a very wet summer, an epidemic commenced in September. In 1870, again in September, another epidemic commenced.

The first cases in 1860 were all supplied from a well which is 32 feet deep-i.e., from surface of ground to surface of water (it has been made lower since 1860 , but was then a deep well). It is near the bottom of the hill. The second batch of cases in 1860 were at the top of the hill, and were supplied with water from a shallow surface well ; a new one, 13 feet deep, has since been made.

In the $1870-1$ epidemic, the first cases were using water from a surface well near the bottom of the hill, and the second batch, water from a well $9_{2}^{1}$ feet deep, and half-way up the hill.

In the yard called Billing's I have not had a case of typhoid, though, with the rest of the village, it has been visited by scarlet fever. There are no manure heaps nor privies in this yard, the privies being at a considerable distance down the hill, while the well is quite at the top of the hill, the depth being 15 feet 6 inches from surface of ground to surface of water. A privy in the adjoining yard may possibly affect it.

I remain, Sir, yours very faithfully,

Grimston, Lynn, Norfolk, Dec. 18, 1871.

A. E. Barrett.

\section{IRELAND.}

(FROM OUR OWN CORRESPONDENT.)

THE annual meeting of the Belfast General Hospital was held last week in the Town Hall, Belfast, under the presidency of the Mayor. The honorary secretary, Mr. Macrory, submitted the report of the general committee, from which it appeared that the total income of the institution from all sources, during the year, amounted to $\& 1793$, as compared with $\$ 4260$ of the preceding year. The medical school connected with the hospital continues to be a decided success, and, during the year, 144 students attended the lectures and hospital dressings, being 32 over last year. Mr. Macrory also submitted a report in reference to the establishment of a Nurses' Home and Training School in connexion with the hospital. The reports having been adopted, a resolution was passed, on the motion of $\mathrm{Dr}$. Browne, R.N., expressing deep sympathy with the Queen and the Princess of Wales in the anxiety and distress caused by the illness of the Prince of Wales.

A munificent donation has lately been made by Samuel Martin, Esq., of Belfast, who has purchased twenty-eight acres of land in one of the healthiest and most picturesque sites in the vicinity of that town, which he intends to hand over, clear of rent, to trustees for the following purposes :One-half to be devoted to the erection of cottage-hospitals for orphan children, preference being given to those suffering from spinal affections. On the construction of these hospitals Mr. Martin purposes to expend $\$ 2000$, and to give them an endowment of $\$ 1000$ a year for at least five 